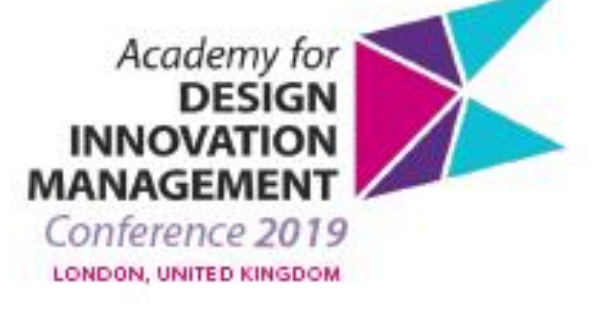

18-21 JUNE 2019

Research Perspectives

INTHE ERA OF

Transformations

\title{
Design practices for strategic innovation in start-ups
}

\author{
GLAUBERT Daphna ${ }^{a b *}$; CHARLESWORTH Zarina ${ }^{a}$; NYFFELER Nathalie ${ }^{a}$ and BERGERON Luc ${ }^{b}$ \\ ${ }^{a}$ HEIG-VD, The School of Management and Engineering Vaud, HES-SO, Switzerland \\ ${ }^{b}$ ECAL, University of Art and Design Lausanne, HES-SO, Switzerland \\ * corresponding author e-mail: daphna.glaubert@heig-vd.ch \\ 300
}

\begin{abstract}
This paper looks at the use of design practices in start-up firms for the creation of strategic advantage through product/service innovation. Start-ups face non-negligible challenges during the early-stage of development. The research questions examined to what extent design practices can provide the leverage needed to face these challenges. A 4-day Innovation by Design Challenge workshop provided the field for the research carried out. Participants were start-up firms each working together with two designers to form six teams. Methods used included: observation for the mapping of team activities; a short selfreport questionnaire and; pre- and post-workshop semi-directed interviews with the startups. The findings support the idea that design practice integration into the initial development of a start-up can indeed provide a lever for success and provide the start-up with the strategic vision needed to go through the early-stage and bring their products/services to market successfully.
\end{abstract}

Keywords: Start-ups, design practice, co-design, innovation

\section{Introduction}

In a recent article on the nature and desirability of innovation, Pisano $(2019$, p. 19) reminds us of the difficulty that organizations have in both creating and sustaining it. Yet in a constantly changing world, innovation becomes a necessity and this even in the case of early-stage start-ups. The question is then what options are available to such firms that allow for the agility necessary for quick market response and, at the same time the creation of a competitive edge? Among the contenders one finds design practices.

This research focuses on how such practices can be made to work and leveraged strategically by an early-stage start-ups for the creation of new opportunities or to improve its product/service through the use of a humancentred approach. Young firms often do not go so far as to have well-written strategic agendas despite having an ear to the ground and an understanding of the importance of providing a product/service in line with what the market requires. Design practices can lead to "meaningful innovation [which] puts together real users' problems and expectations with new technologies or a new use of a known technology" (Rossanese, Zilse, Arantes, \& Tobias, 2017, p. 3)

There is an ever increasing need to integrate diverse areas of knowledge "where the ability to work across boundaries represents a key ingredient for competitive advantage" (Hacklin \& Wallin, 2013) in which co-design and design thinking methodology play an important role and where "design thinking can be defined as the application of design methods by multidisciplinary teams to a broad range of innovation challenges" (Seidel \& Fixson, 2013, p. 19). Furthermore, the integration of a design perspective means that "the emphasis is transposed from business need to user need" (Newton \& Riggs, 2016, pg 2) placing the user at the start of the design process rather than at the end. 


\section{Literature review}

It has been noted, more than once, that the appropriate deployment of design resources allows a firm to achieve its organizational objectives (Gorb, 1990) and to foster value creation (Borja de Mozota, 2006). Although particularly true for large companies (Design_Council, 2007), this also applies to young structures such as start-ups. Reported research focusses largely on the implementation and use of design practices in large organisations (Bau, 2016) with a smaller body of literature reserved for small businesses (Acklin \& Hugentobler, 2008; Malins, 2011; Ward, Runcie, \& Morris, 2009). In large part, the design practice literature does not differentiate between established firms, large or small, and start-ups. We believe that there is indeed a difference here which has, in turn, guided our research. This section presents the challenges faced by startups and how design practices can provide a strategic response to them within the framework of current models and methods.

\section{Specificities of Start-ups}

Whether start-ups are presented as the result of the entrepreneurial act (Chew, 2015), or as "a human institution designed to deliver a new product or service under conditions of extreme uncertainty" (Ries, 2011, p.8) their activity focuses on the development of ideas, opportunities and the design of new products or services. All start-up firms can be seen to go through several clearly identified phases and all generally face the same challenges.

The start-up development goes through different stages that include (1) the Bootstrapping stage (2) the Seed stage and (3) the Creation stage (Radovic-Markovic \& Salamzadeh, 2012). Those stages are used to transform the entrepreneur's idea into a profitable business. The objective is to position the company by demonstrating the feasibility and acceptability of its product to customers as well as its financial capacity and team management skills (Brush, Carter, Gatewood, Greene, \& Hart, 2006). Companies increasingly recognize the importance of design during the early-stages, also known as the Fuzzy Front End, by using the skills of designers not only for the realization of new products/services, but also for the co-creation of concepts (Calabretta \& Gemser, 2016).

In the early stages start-ups generally do not have the luxury of time nor money yet need to reduce the risk of failure to a minimum and a lack of resources can prevent the start-up from collaborating with a designer from start to finish. Working under such constraints (Glaubert, Nyffeler, \& Bergeron, 2018) can contribute to the high failure rate exhibited by start-ups especially during the early-stages where the risk of failure is omnipresent.

Liedtka (2018) suggests that design practices, particularly design thinking, can be regarded as a social technology which she defines as a "blend of tools and insight applied to a work process" and goes on to suggest that "it has the potential to do for innovation exactly what TQM did for manufacturing" (p. 72), in addition to answering the challenges that firms face in the innovation process including the identification of superior solutions and the lowering of risks and costs. She joins, to a certain extent, the position taken by Acklin and Wanner (2017) that design practices are more than design but should be considered a management function, one that "embeds design or design processes in companies in order to create added value in products, services, experiences, processes and structures" (p. S471).

Despite a dearth of research on the challenges faced specifically by start-ups there seems to be a general consensus that such firms face similar challenges and ones other than those faced by established firms. Giardino, Bajwa, Wang \& Abrahamsson (2015), identified ten critical challenges faced by start-ups based on a world-wide sample of 4709 start-ups and which include resource (financial, human and physical) and market related issues. This corroborates what has already been said about keeping financial and time investments down all the while paying particular attention to market needs.

Seen from this point of view it becomes clear that start-ups particularly serve to gain from collaboration between those who have competencies complementary to their own, namely, designers. And this, despite a reticence on the part of a certain category of start-ups as "budding entrepreneurs from the engineering disciplines often associate the term 'design' with art and as not relevant for their future business" (Acklin \& Wanner, 2017, p. S470). Design allows for a user-centred focus and "humanizes" (Buchanen, 2000) the technology, of importance when start-ups, particularly high-tech start-ups, are looking for investors or are in the process of addressing future clients. 
The integration of design practices can be seen as a key success factor and a risk-reducing one, something of high importance for young start-ups in the early-stage (Sheppard, Kouyoumjian, Sarrazin, \& Dore, 2018).

\section{Innovation by design}

As mentioned in the introduction, we live in a fast-paced world, one where innovation has become something of an overused buzzword. This banality has today's consumer taking novelty as a given and expecting to see it with ever greater frequency. Some talk about design as the latest best answer to innovation with Owen (2006) going so far as to say that design thinking "offers a way of approaching issues, problems and opportunities almost uniquely suited to innovation" (p. 3). Yet design practices alone will not suffice, nor should one imagine them as the Holy Grail to start-up success.

Both design and innovation are used with ever greater frequency, as well as interchangeably, to describe a method comprising products, services and systems. If design can indeed be seen as a resource, it is closely tied to the user and can translate into an advantage as the focus is on the human aspect versus that of the technology (Kolko, 2007). Monori, Arruda and Araujo (2015) suggest that successful innovation depends on "the understanding of user needs, competitive advantage and synergy between the company's strengths" ( $p$. 2201).

The role of design in innovation has long been under discussion, see for example Roy (1994) for an initial discussion of how design supports innovation and Na, Evans, Zitkus, Whicher and Walters (2018) for one more recent. Its role in incremental and radical innovation was also well described by Borja de Mozota (2003).

In a recent report published the British Design Council (Benton, Miller, \& Reid, 2018), design is identified as a resource for innovation with survey results showing that firms placing importance on design activities and with "design functions or facilities in-house are significantly more likely than average to have developed completely new and original products, services or processes" (p. 28). Over the past twenty years design has taken an everincreasing role in the creation of unique and innovative marketing approaches and is increasingly seen as a method of ideation to be used by both design and non-design firms (Kolko, 2007). Today design is taking on a further element of importance as it allows for the development of products and services that have meaning for the customers and it "has the ability to add value in many ways, including economic, social, and environmental” (Lockwood, 2007, p. 91).

Despite an accrued interest in design practices, there is little empirical evidence (Malins, 2011) to support long term results of using such practices for innovation. Firms must be aware that such practices need to fit with company values and that they are but one option to choose from.

\section{Co-design}

The integration of design practices within startups requires knowledge of multidisciplinary collaboration and co-design. Indeed, they are an integral part of the design thinking methodology where different stakeholders are integrated into the project's thinking to address broader innovation challenges. The term co-design has more than one definition going from its restriction to designers alone or to a more all-encompassing definition put forth by Sanders and Stappers "co-design in a broader sense to refer to the creativity of designers and people not trained in design working together in the design process" $(2008$, p. 6). Such collaboration allows the firm to step back and view the project in question from an alternative point of view. In the words of Schwartz, Bransford and Sears "we think it is especially important to note that innovation often requires a movement away from what is momentarily most efficient for the individual or the organization" $(2005$, p. 30). This calls on the firm to invest some of its limited time resource to pause and reflect upon questions frequently asked by designers including what the purpose of the innovation is; who the target user is and; how it will be used.

Although the ideas of co-design have been around for some time now and, with the design domain, can be seen to have their roots in the participatory design movement of the 1970's (Sanders \& Stappers, 2008), it would seem that industry was not ready until recently, however, to embrace these principles.

\section{Crossing disciplinary boundaries}

Taking the debate one step further we looked at the research on team composition within design practice. Much of the literature ignores the fact that design practice teams are often interdisciplinary and look more at 
team dynamics and successful team performance. Yet interdisciplinary teams have an additional level of complexity which should be taken into account if one is to achieve the desired "interdisciplinary knowledge integration [which] depends on the ability of individuals in teams to combine knowledge in novel ways" (Hacklin \& Wallin, 2013, p.781).

In addition to the disciplinary differences that one might find among team members and, of particular interest in our research, are Ho's (2001) research findings which suggest that there is "an obvious difference between experts and novices in the way they approach the problem" (2001, p. 43). Expert designers were found to look at the design problem before using working-backward strategies to come up with design knowledge in answer to the problem whereas novice designers tended to use working-forward strategies in search of design solutions already at the outset (Ho, 2001).

In summary, what design practices today can most benefit from is teams which have the support necessary to allow for boundary-crossing by the individuals concerned to function optimally. This might take the form of models, processes, or even toolkits to help structure and allow for the integration of such practices.

\section{Design in practice}

\section{Models and methods}

By the early 2000's design practices came to be seen as a "complex thinking process of conceiving new realities, expressing the introduction of design culture and its methods into fields such as business innovation" (Tschimmel, 2012, p. 2). With this, reference to and attempts to adopt design thinking became increasing widespread. In order to facilitate the use of design thinking a number of models were created to allow for its integration into any organisation.

The most notable among these were the IDEO models which included the $3 \mathrm{I}$-Inspiration, Ideation and Implementation and the Hearing, Creating, Delivering HCD models (Tschimmel, 2012). Two other important contributions to the model literature were the Double Diamond model introduced by the British Design Council (British Design Council, undated) and the Service Design Thinking (SDT) model (Stickdorn \& Schneider, 2011)

As an alternative to the phase/step approach provided by the models, a number of authors, focused on the identification of key questions to be addressed during the design process. This includes research done by Austin et al. who in some early work on interdisciplinary design teams (2001) found the process to be iterative. Although no structure or method resulted from their work, they did note that without any guidance the teams studied proceeded in an ad hoc manner. Liedtka (2014) highlights the importance of what she identifies as the 'questioning period' with four essential questions to be asked: what is, what if, what wows, what works in order to create not only successful but productive teams.

Complementary to the model-based approach one also sees a number of process-related methods including that developed by Google Ventures and shown in Table 1.

Table 1: GV Design Sprint process

\begin{tabular}{|c|c|c|c|c|}
\hline Day 1 & Day 2 & Day 3 & Day 4 & Day 5 \\
\hline UNDERSTAND & DIVERGE & DECIDE & PROTOTYPE & VALIDATE \\
\hline $\begin{array}{l}\text { - who are the users } \\
\text { - what are their needs } \\
\text { - what is the context } \\
\text { - competitor review } \\
\text { - formulate strategy }\end{array}$ & $\begin{array}{l}\text { - envision } \\
\text { - develop lots of } \\
\text { solution } \\
\text { - ideate }\end{array}$ & $\begin{array}{l}\text { - choose the best idea } \\
\text { - storyboard the data }\end{array}$ & $\begin{array}{l}\text { - build something quick } \\
\text { and dirty to show to } \\
\text { users } \\
\text { - focus on usability not } \\
\text { making it beautiful }\end{array}$ & $\begin{array}{l}\text { - show the prototype } \\
\text { to real users outside } \\
\text { the organisation } \\
\text { - learn what doesn't } \\
\text { work }\end{array}$ \\
\hline
\end{tabular}

The afore-mentioned process combines elements of existing models with guidance on how to proceed at each stage. This provides a framework that, for those new to design, can allow for a structured adoption process. 
Finally, we now find an increasing number of design practice tool-kits available aimed at the smooth integration of design practices into business, just a few of which are listed in the references (Calabretta \& Gemser, 2016; IDEO.org, 2015; Sanders \& Stappers, 2013).

In summary, design practices for early-stage start-ups is a field that has not been the subject of much empirical research and one which we esteem could be a viable strategic option for such firms helping them to face typical start-up challenges. This has influenced our research focus and led us to define the following research questions:

Within the framework of a 4-day workshop open only to early-stage start-ups and designers:

1. What are the key activities used to solve a short-term design objective?

2. What is the team's perception of its productivity, collaboration and individual involvement?

3. To what extent might design practices be seen as a strategic option for start-up firms?

The answers to these questions will provide the basis for the identification of best practices with the intent to develop a method accompanied by specific tools for strategic innovation through design in start-up firms.

\section{Methods}

We chose to use action research in order to carry out this project as, more than any other paradigm, it takes the interests of all stakeholders into account (du Preez, 2011). Based on the framework set out by Dick (1993) we have followed three defined steps: intention, action and, review. These headings are used below to present the research carried out in what is the second iteration of the project. Results from the first iteration (Glaubert et al., 2018) allowed for the continued development of the $2^{\text {nd }}$ Innovation by Design Challenge (IDC) the results of which are reported in this paper.

\section{Intention}

In order to provide an opportunity for start-up firms to test design practices as a strategic tool for competitive advantage we organized for the 2nd time, an annual a 4-day, evening-only, workshop called "Innovation by Design challenge". Our intent was to foster collaboration between start-ups and designers allowing the startups to improve their products/services through design practice angle. Six start-ups and twelve designers worked actively during four three-hour evening sessions over consecutive days with a final presentation one week later. This programme was designed and implemented by the School of Management and Engineering Vaud (HEIG-VD) and the ECAL/Ecole cantonale d'art de Lausanne and sponsored by a Swiss municipality (Ville de Renens) and an organisation supporting entrepreneurship in the state of Vaud (Innovaud) (Figure 1).

\section{Action}

This stage called for the implementation of the action research which, within the framework of the workshops, included active observation, informal participant feedback, the completion of a self-report questionnaire and, semi-directed interviews held with the start-ups involved.

From the first iteration of the challenge we learnt that some designers had difficulties in understanding the start-up's objectives and the short-term issues they wanted to find solutions for. As the result depended on the designer's knowledge and ability to work with the start-up this was a critical issue. In order to foster quality collaboration, we chose a more structured format with set milestones for the 2nd iteration, the results of which are presented here.

The proposed workshop drew upon two complementary models. The rationale for this being that design practices in entrepreneurial organisations alternate between open, explorative approaches on the one hand and more focused, specific ones on the other (Nguyen, 2016). The more explorative "Double Diamond" approach of the British Design Council (British Design Council, undated) has four phases: Discover, Define, Develop and Deliver, phases that allow the participant to meander. The focused method selected was the product design sprint process developed by Google Venture (Knapp \& Zeratsky, 2016) a structured method using specific tools to achieve rapid prototyping within a short period of time. 
Using our knowledge of the two approaches and given the five collaborative sessions at our disposal, we created four phases to structure the workshop: Reframe, Imagine, Realize and Present. These are presented below.

1. Reframe :

Where we introduce the challenge and help to build a common understanding of the existing product and its context (clients, usability, business model, problems encountered, constraints). Then at the end of the first session all teams are asked to formalize the challenge that they want to address during the workshop. As in the previous challenge, we sent a list of questions to the start-ups to prepare prior to the first session and asked all teams to formulate the problem they wanted to solve during the workshop with two questions: HMW (How Might We) question and the value proposition question (Osterwalder \& Pigneur, 2014).

2. Imagine:

The second and the third sessions concentrates on proposing one or more solutions with a focus on customer experience and the use of the product/service, followed by the selection of one of the proposed solutions and its subsequent development.

3. Realize:

The fourth session is dedicated to the production of visual materials (presentation, prototype) in order to help pitch the projects to the public.

4. Present :

The fifth session is devoted to the final presentation.

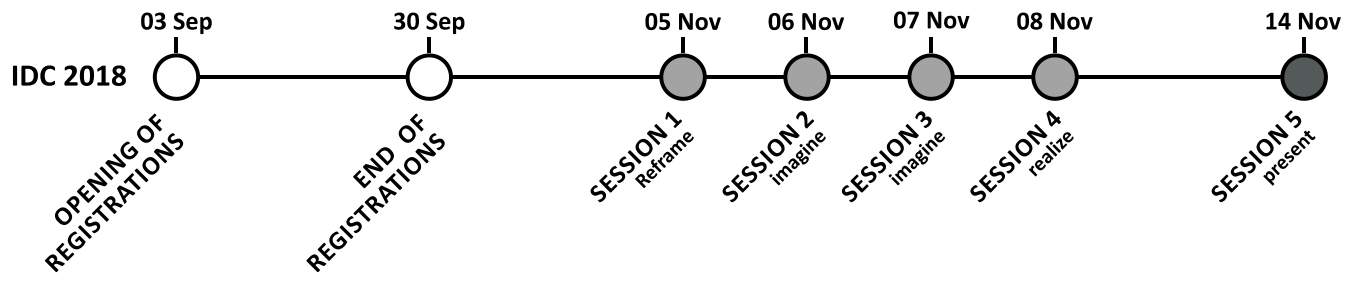

Figure 1: The entire workshop programme

Participants: In order to select the teams a call for start-ups and designers was launched between 03rd September 2018 and 30th September 2018. A total of eleven start-ups and nineteen designers applied. The criteria were the same as in the first iteration : start-ups were (1) to be located in the state of Vaud; (2) to have been founded in the last five years or to be in the creation phase and; (3) to propose an innovative project; designers were (1) to be a final-year Bachelor's or Master's student or a professional under 40 years of age. The choice of start-ups took into account the needs and short-term objectives stated on the application form. Six start-ups and twelve designers were selected for the challenge, each start-up was assigned 2 designers with complementary knowledge, experience or studies background (table 2). Indeed, the start-up challenge requires several disciplines in design to solve it. Several designers had multiple design skills and two teams (team $\mathrm{D}$ and $\mathrm{F}$ ) benefited from the experience of a senior designer (having more than 10 years of experience) and with knowledge of design thinking and the strategic approach of design (Service design or experience design or MBA background).

Table 2 : Start-up workshop participant and designer profiles

\begin{tabular}{|c|c|c|c|c|c|c|}
\hline Start-up & $A$ & $B$ & $C$ & $D$ & $E$ & $F$ \\
\hline Creation & Feb, 2016 & Dec, 2017 & Jul, 2015 & Sep, 2016 & Fev, 2017 & Jun, 2017 \\
\hline $\begin{array}{l}\text { Sector of } \\
\text { activity }\end{array}$ & $\begin{array}{l}\text { Industrial } \\
\text { Machinery } \\
\text { and } \\
\text { environment }\end{array}$ & $\begin{array}{l}\text { Industrial } \\
\text { machinery }\end{array}$ & $\begin{array}{l}\text { Optics, } \\
\text { mechanics, } \\
\text { software, } \\
\text { engineering }\end{array}$ & $\begin{array}{l}\text { Drones, } \\
\text { infra- } \\
\text { structure }\end{array}$ & Transport & $\begin{array}{l}\text { Planning and } \\
\text { management } \\
\text { of end-of-life } \\
\text { data }\end{array}$ \\
\hline
\end{tabular}




\begin{tabular}{|c|c|c|c|c|c|c|}
\hline Main offer & $\begin{array}{l}\text { Machines } \\
\text { capable of } \\
\text { collecting } \\
\text { lake algae } \\
\text { and } \\
\text { transforming } \\
\text { it into } \\
\text { powder. }\end{array}$ & $\begin{array}{l}\text { Efficient and } \\
\text { effective } \\
\text { beverage } \\
\text { machinery }\end{array}$ & $\begin{array}{l}\text { Planar } \\
\text { micro- } \\
\text { tracking } \\
\text { system that } \\
\text { can redirect } \\
\text { light in } \\
\text { various } \\
\text { direction }\end{array}$ & $\begin{array}{l}\text { Detect } \\
\text { drones in air } \\
\text { traffic to } \\
\text { avoid } \\
\text { collisions }\end{array}$ & $\begin{array}{l}\text { Participatory } \\
\text { workshop on } \\
\text { motorcycle } \\
\text { and bicycle }\end{array}$ & $\begin{array}{l}\text { Secure } \\
\text { digital } \\
\text { platform } \\
\text { that stores } \\
\text { all important } \\
\text { information } \\
\text { at the end of } \\
\text { life }\end{array}$ \\
\hline $\begin{array}{l}\text { Full-time } \\
\text { employee } \\
\text { (FT) }\end{array}$ & 3 & 2 & 10 & 6 & 3 & 6 \\
\hline Needs & $\begin{array}{l}\text { Present your } \\
\text { product in a } \\
\text { simplified } \\
\text { way }\end{array}$ & $\begin{array}{l}\text { Review the } \\
\text { product } \\
\text { design for } \\
\text { production } \\
\text { launch. }\end{array}$ & $\begin{array}{l}\text { Clarify our } \\
\text { message to } \\
\text { our potential } \\
\text { prospects }\end{array}$ & $\begin{array}{l}\text { Redesign the } \\
\text { digital } \\
\text { platform }\end{array}$ & $\begin{array}{l}\text { New identity } \\
\text { to reach new } \\
\text { customer }\end{array}$ & $\begin{array}{l}\text { Invent a } \\
\text { complete } \\
\text { experience } \\
\text { around an } \\
\text { emergency } \\
\text { card }\end{array}$ \\
\hline Designer 1 & $\begin{array}{l}\text { Product } \\
\text { designer }\end{array}$ & $\begin{array}{l}\text { Product } \\
\text { designer }\end{array}$ & $\begin{array}{l}\text { Product } \\
\text { designer }\end{array}$ & UX designer & $\begin{array}{l}\text { Service } \\
\text { designer }\end{array}$ & $\begin{array}{l}\text { Product } \\
\text { designer }\end{array}$ \\
\hline Designer 2 & Architect & $\begin{array}{l}\text { Product } \\
\text { designer }\end{array}$ & $\begin{array}{l}\text { Product } \\
\text { designer }\end{array}$ & $\begin{array}{l}\text { Architect } \\
\text { and design } \\
\text { strategist }\end{array}$ & $\begin{array}{l}\text { Product } \\
\text { designer }\end{array}$ & $\begin{array}{l}\text { Senior } \\
\text { product } \\
\text { designer and } \\
\text { design } \\
\text { strategist }\end{array}$ \\
\hline
\end{tabular}

Data collection : During the Challenge, we collected three data sets. The first data set was based on an observation of the activity of each team during the three first sessions. The list of the activities of each group have been quantified and classified according to the nomenclature of the phases of the double diamond model, namely discover, define, develop, deliver. Our intention was to use this data to map the creative activities and identify divergent and convergent moments. The second set of data collected during the sessions concern the perception of collaboration. Each member was asked to answer to a short self-report, 8-item questionnaire at the end of the session in order to better understand the team dynamics, their alignment on the process and their perception of the collaboration, engagement and productivity. The team B didn't answer the questionnaire the second evening, their data is excluded from our analysis. The third data set concerned the semi-structured interviews with the six start-up managers. We used an interview guide to conduct the semi-structured interviews held at two time periods: T01 = before the workshop, T02 = after the workshop. This set of data focus on the awareness of design, the role of design for the start-ups, and their expectation of the Challenge.

\section{Review}

The final stage of an action research approach calls for review. After the $1^{\text {st }}$ iteration of the IDC workshop an informal review was done in order to revise and prepare for the $2^{\text {nd }}$ iteration reported here. This in turn will be subject to review prior to the $3^{\text {rd }}$ workshop planned for 2019.

\section{Research findings / data analysis}

The aim of the observations was to analyse the creative process of each team in order to validate and improve the tools used during the workshop sessions and identify the critical activities to foster collaboration between the start-ups and the designers. 


\section{Creative process}

The observations allow us to list the activities of each team and visualize their creative process according to the double diamond model. We distinguished teams with novice designers $(A, B, C, E)$ and teams with senior designers $(D, F)$. As per the results, the novice designer teams do not follow the double diamond process in a linear way. Indeed, for teams A, B, E, the develop phase can occur regularly from the first S1 session and the define phase appears several times throughout the process for teams $A, B, E$ until the last S4 session for teams C. In addition, it is noted that teams with senior designers follow a process closer to the double diamond model with distinct phases. The discover and define phase appears in time S1 for team D and continues in S2 for team F. The develop phase extends to S2 and S3. Finally, the production phase appears in S4. This shows us that the first phase also has a relatively dense number of activities and that the definition of the in-depth problem allows us to develop solutions without having to come back to the define phase to figure out on the problem.

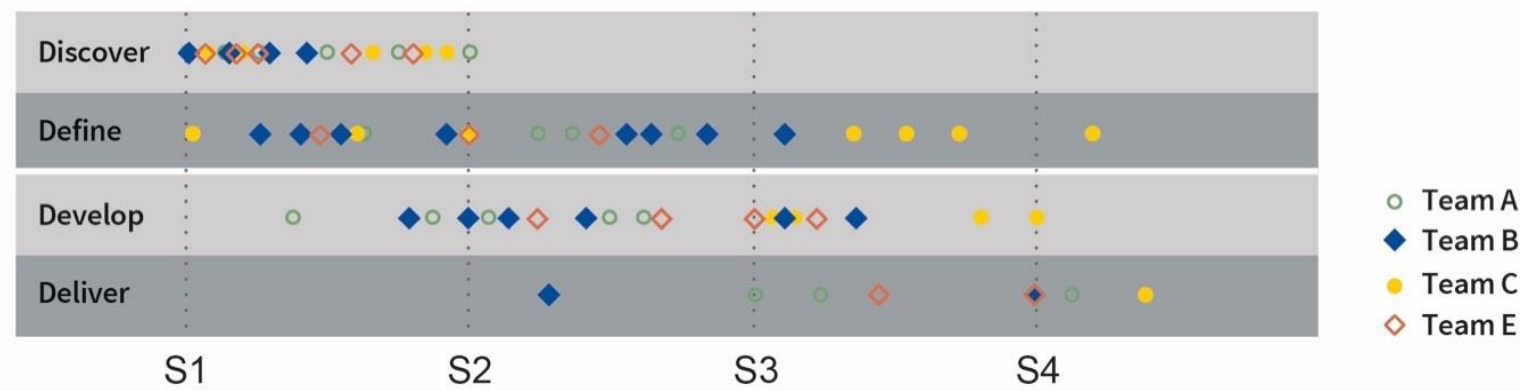

Figure 2 : Mapping of the activities of novice designer's team

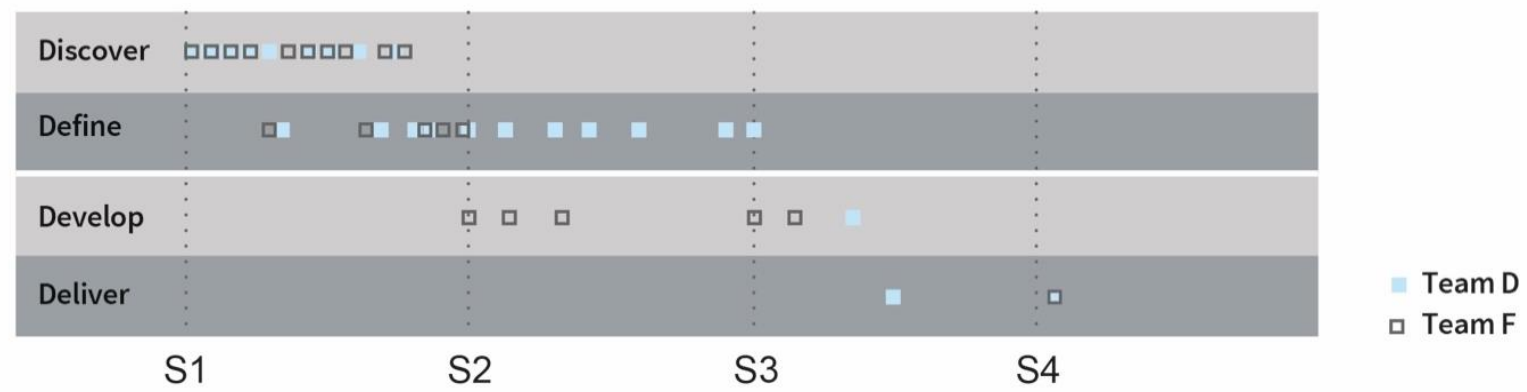

Figure 3 : Mapping of the activities of senior designer's team

The management of the creative process seems to have an influence on the perception of the team production, collaboration and individual implication. The result of the questionnaire links team activities to the collective and individual perception of collaboration.

\section{Perception of collaboration}

The results show that the quality of the production is estimated lower when they enter the define phase and increases for the develop and deliver phase and that this varied from one team to another (Figure 4). For example, Team $C$ encountered difficulties in defining the start-up's problems and needs. Their perception of their collaboration was at its lowest in S3 at which time they were still defining the problem to be solved (Figure 2). Teams E and F started the development phase in session 2 whilst Team D did not start the development phase until session 3 (Figure 3). Teams A and B followed a more iterative process and both improved and stabilized their collaboration in session 3. The data show that the teams perceive that they have performed better as a team when they agree on, and subsequently follow, a design process. Finally, the assessment of productivity, involvement and collaboration of all the teams improved at the develop and deliver phase. 


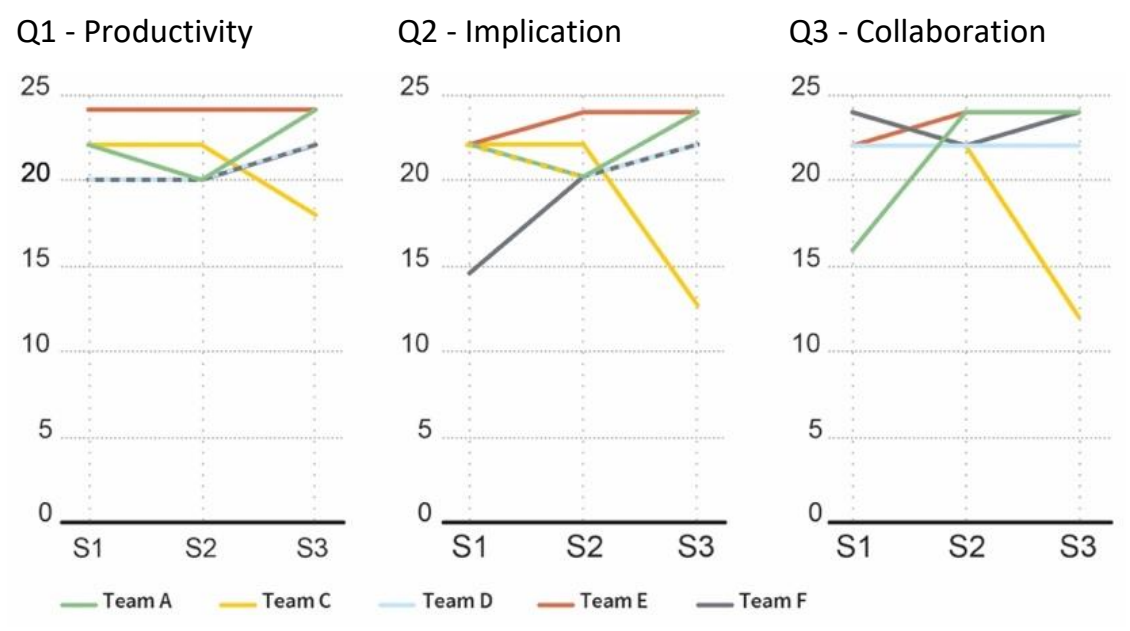

Figure 4 : Team perception of their productivity, involvement and collaboration

The analyses and themes mentioned during the different phases allowed us to see that the develop phase ends when the teams have a complete understanding of the value of the product and how it is used (competitor, stakeholders, technical, prototype, problems encountered, Unique Selling Proposition, offer); the customer segment (who the main customers are and what their needs are) and the short term objective (the problems to solve, the constraints, the deliverables). For the senior teams, they also tried to understand the business model and define the unique selling proposal or value proposition (table3).

\section{Activities and milestones of each phase}

The synthesis of the teams' activities during the program shows similarities between the teams' activities and those proposed by the sprint model. Indeed, the identification of target customers, their needs / experience, as well as dividing the challenge into sub-questions and objectives are key elements of the reframing phase. In the context of the challenge, several areas of reflection (industrial, service, digital interactions), designers also evaluate the offer, the added value of the product and its use. The difference between the models can be explained by the type of participants. Indeed, the sprint allows employees who do not have any knowledge of design to actively participate in the creative process, while in the IDC Challenge is formatted for one manager of startups with a predominance of designers. Thus, the creative process is still structured with exercises inspired from the sprint workshop model during the diverge, decide and prototype phases while the imagine and develop phases depend on the knowledge and methods used by the designers. Nevertheless, we find milestones for the development phase with the realization of prototypes, iteration, validation of the concept, distribution of tasks.

Table 3 : Synthesis of the activities during the phases

\begin{tabular}{|c|c|c|c|c|c|}
\hline $\begin{array}{l}\text { Double } \\
\text { diamond }\end{array}$ & DISCOVER & DEFINE & DEVELOP & DELIVER & \\
\hline \multirow[t]{5}{*}{ IDC } & REFRAME & REFRAME & IMAGINE & \multirow{5}{*}{$\begin{array}{l}\text { DEVELOP } \\
\text { (6) Prototyping } \\
\text { (6) Iteration } \\
\text { (6) Validation of the } \\
\text { concept }\end{array}$} & \multirow{9}{*}{$\begin{array}{l}\text { PRESENT } \\
\text { (6) Pitch }\end{array}$} \\
\hline & \multicolumn{2}{|c|}{ Understand the company context } & (6) Ideas & & \\
\hline & \multicolumn{2}{|c|}{ (6) Company context } & (6) Inspirations & & \\
\hline & \multicolumn{2}{|c|}{ (2) Competition } & (6) Evaluation & & \\
\hline & \multicolumn{2}{|c|}{ Understand the product value } & & & \\
\hline \multirow[t]{5}{*}{ Activities } & (6) Product & (2) USP & & \multirow{2}{*}{$\begin{array}{l}\text { (6) Task distribution } \\
\text { (6) Production }\end{array}$} & \\
\hline & understanding & & & & \\
\hline & \multicolumn{2}{|c|}{ Understand how the product is used } & & \multirow{2}{*}{$\begin{array}{l}\text { (6) Visual } \\
\text { presentation }\end{array}$} & \\
\hline & (6) Usability & (2) Constraints & & & \\
\hline & (3) Technical as & & & & \\
\hline
\end{tabular}




\section{Define the customer segment}

(6) Customer segment

(6) Pick a target \&

understand needs

Define the short term objective

(6) Problem to solve

(6) Objectives

(6) Deliverables

(6) HMW
(6) Pitch

preparation

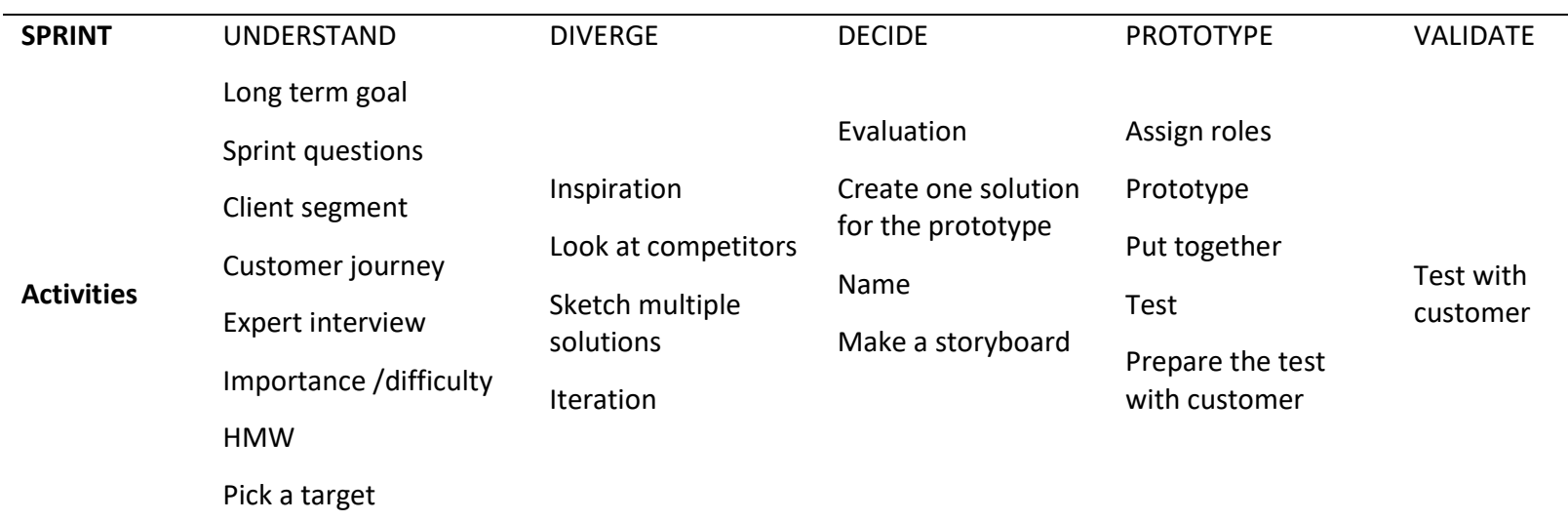

\section{Design as strategic role}

The semi-structured interviews provided insight into the perception of design by start-up managers both before and after the event. Clearly the collaboration with the designers allowed the managers to understand that design had a strategic role in positioning their offer and client product acceptance (table 4).

Table 4 : Definition of design by the six managers

- Cannot give a definition (3)

- Solve a technical problem, a way of producing a product (2)

- $\quad$ Link to communication, identity, marketing advertising (1)

- Interact with products and take into account beauty and production criteria to

Before differentiate from the competition (1)

- Understand and meet the user's needs (1)

- Visualise a process (1)

- Make a shape attractive to the eye (1)

- Demonstrate empathy (1)

\begin{tabular}{lll}
\hline & - Links between technology, innovation and society (1) \\
After & - Transform innovation to make it accessible (1) \\
& - Redefinition and improvement of the company's tangible and intangible values (1) \\
- & Bnderstand a context and the needs (1) \\
- Simplify a product in a pleasant and effective way (1) \\
\hline
\end{tabular}

Five teams believed that working with designers exceeded their expectations and allowed them to take a step back from their product and the issues they wanted to solve. Three teams reviewed the initial product and focused on support of communication of the offer. Collaboration with designers helps the start-ups on the following goals :

- A step back on the product or the issue (5)

- The creation of a tangible solution to present to customers (5)

- $\quad$ Simplifying the message (3) 
- The integration of several design disciplines to create a coherent global project (3)

\section{Discussion}

With the Innovation by Design Challenge (IDC) we aimed to give an impulsion to start-ups by collaborating with designers on short-term objectives. The IDC was also to provide answers to our research questions. The first question had to do with the key activities used to solve a design objective in the short term. Our findings suggest that design practices can be a strategic step in the transformation of an innovative technology into a significant product by focusing on user interactions. Indeed, to solve the design challenge, the designer must define 3 main elements such as (1) the added value of the product/service, (2) who is the main customer and/or user, what are their needs, pains and motivations, (3) and how the product is used. While senior designers quickly capture these elements, young designers tend to have a more organic approach and oscillate between the definition and ideation phases, which can sometimes be difficult in terms of collaboration.

The second question that we addressed was whether such teams would be perceived by the team members as productive, collaborative and involving all team members. From what we have seen during the first two iterations of IDC, the answer is that the perception, in all categories, was positive. In line with what previous research has shown (Ward \& Al. 2009), we found that introducing experienced designers to a start-up can stimulate innovation and create new opportunities. For the start-ups, working with individuals having diverse design backgrounds allowed quick results to be achieved and helped the firms to focus on their main clients.

In response to our third question, design practices were also welcomed by the IDC participants as a potential strategic option and seen to allow for the transformation of an innovation into a useful and accessible product/service for users. While market acceptance is a crucial element for the growth of start-ups, the practice of design with multiple disciplines seems to improve product consistency by focusing on the user experience. Collaboration with a designer makes it possible to make the link between the technology, the user and the context of the product/service following the phases of the creative process. Indeed, the observation of the teams allowed us to understand the collaboration process between start-ups and designers and identify key activities for product and service development. These various activities also allow us to help entrepreneurs step back, simplify the message and create an optimal product experience for users. One can say then that the practice of design consolidates the positioning of the product and validates its future acceptance by customers.

It is also of interest to note that there seems to be some correlation between the senior team process and the one developed during the product design sprint process. Collaboration between designers and start-ups is critical when it comes to understanding and defining the issue. Iterations of the ideation phase can be unproductive and create sources of frustration if the defined phase has not been well resolved beforehand. Project synthesis and scoping tools would facilitate the relationship between participants.

The results of our research suggest that the "reframe" phase could be split into 2 distinct phases : "understand" and "reframe". The list of the activities carried out by the teams during each phase give an indication about the critical point to solve before going to the next phase (figure 6). 


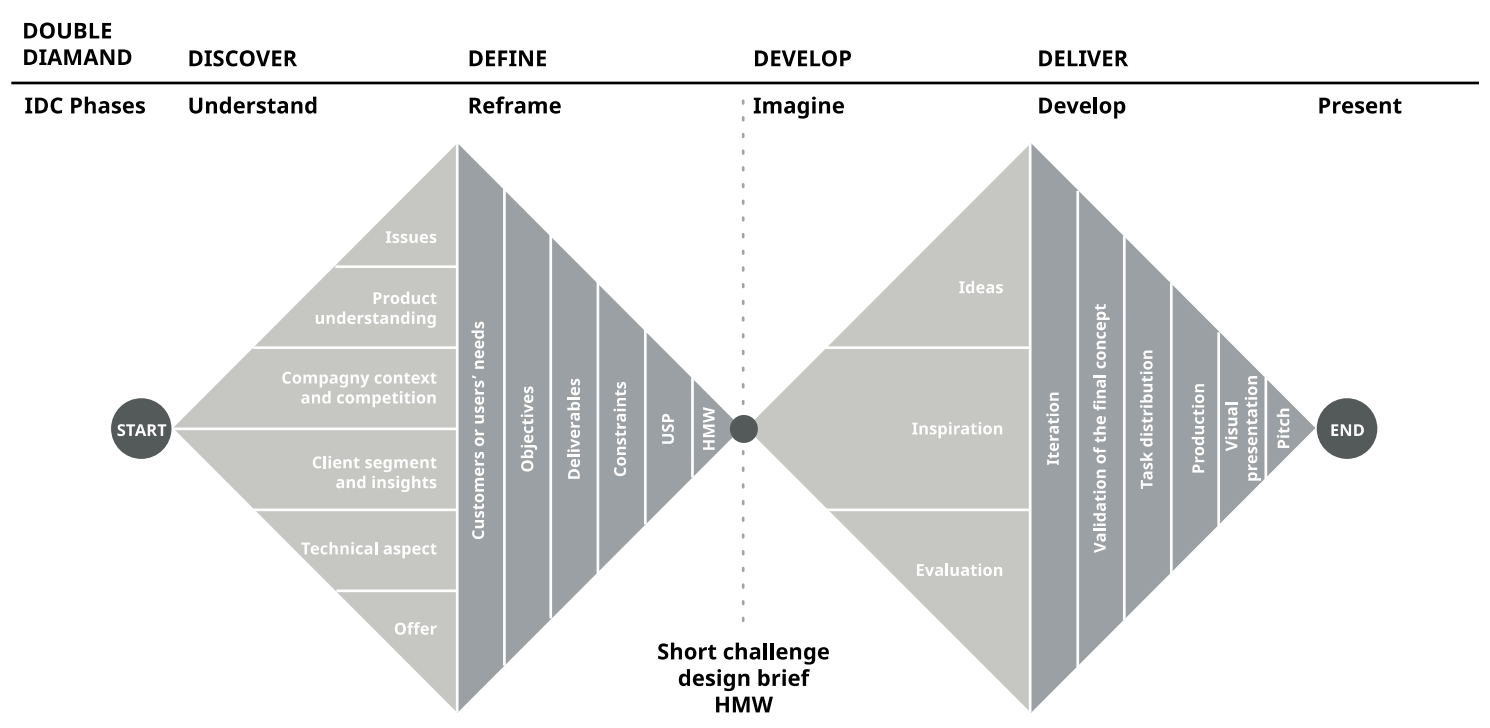

Figure 6 : Guidelines for the next programme

\section{Conclusion}

The use of interdisciplinary design teams for strategic innovation by start-up companies can indeed make a difference allowing them not only to bring potentially successful products to market but also allowing them to face up to other challenges including those of time and risk by engaging in a focussed, relatively high-speed process.

With regard to the limitations of this research presented here, only six teams participated in this study. A wider panel would be needed to achieve more generally applicable results. In the long term, the project has already been planned for 2019 , and will allow us to test a more structured approach to be able to scale up the program and applied it in various incubators in the region. In terms of future developments and in order to scale up this programme we plan to (1) formalize the creative process activities into exercises, (2) find sponsors to help the start-ups finance the workshop programme, (3) create a toolkit to empower teams when collaborating.

In conclusion, success for an early stage start-up means dealing with challenges particular to such firms in a strategic manner so as to them to take their place in the market. Despite the tool-kits and models that abound, little are geared specifically towards early stage start-ups. This research has taken the specific challenges faced by early-stage start-ups as a starting point for an in situ exercise to evaluate the potential impact of design practices. The research supports the idea that such practices can indeed be included at the incubation stage of a start-up to help it better address used needs from a design perspective. Whether this will in turn impact the firm's longevity is another question but at least it provides the firm with a strong, more holistic basis, from which to move forward. While the study shows that design pratcices can become strategic for a startup, start-ups face difficulties in financing the integration of design into early stages of development, and initiatives to facilitate access to design are required.

\section{References}

Acklin, C., \& Hugentobler, H. (2008). Design Management for Small and Medium-Sized Enterprises: Development of a Design Management Guide for the Use of Design and Design Management within Corporate R\&D and Decision Making Processes. Paper presented at the 4th Swiss Design Network Symposium "Focused - Current Design Research Projects and Methods", Bern, Switzerland.

Acklin, C., \& Wanner, A. (2017). Design and design management in the incubation phase of high-tech start-ups. The Design Journal, 20(sup 1), S469-S478.

Austin, S., Steele, J., Macmillan, S., Kirby, P., \& Spence, R. (2001). Mapping the conceptual design activity of interdisciplinary teams. Design Studies, 22(3), 211-232.

Bau, M. N. (2016). Design THinking in Startups. (MSc in Innovation \& Entrepreneurship), Oslo, Oslo. 
Benton, S., Miller, S., \& Reid, S. (2018). The Design Economy: The state of design in the UK. Retrieved from Borja de Mozota, B. (2003). Design Management: Using Design to Build Brand Value and Corporate Innovation. New York: Allworth Press.

Borja de Mozota, B. (2006). The Four Powers of Design. Design Management Review, 17(2), 44-53.

British Design Council. (undated). Design methods for developing services. Retrieved from https://www.designcouncil.org.uk/sites/default/files/asset/document/Design\%20methods\%20for\%2 Odeveloping\%20services.pdf

Brush, C. G., Carter, N. M., Gatewood, E. J., Greene, P. G., \& Hart, M. M. (2006). The use of bootstrapping by women entrepreneurs in positioning for growth. Venture Capital, 8(1), 15-31. doi:10.1080/13691060500433975

Buchanen, R. (2000). Good Design in the Digital Age. GAIN: AIGA Journal of Design for the Network Economy, $1(1), 1-4$.

Calabretta, G., \& Gemser, G. (2016). Integrating design into the fuzzy frontend of the innovation process. In M. G. Luchs, S. Swan, \& A. Griffin (Eds.), Design Thinking: New Product Development Essentials fromthe PDMA (pp. 107-124). USA: John Wiley \& Sons Inc.

Design_Council. (2007). The Value of Design Factfinder Report. Retrieved from United Kingdom:

Dick, B. (1993). You want to do an action research thesis? Retrieved from http:| | www.scu.edu.au/schools/gcm/ar/art/arthesis.html

du Preez, V. (2011). Taking it further : the practical implications of action research. Paper presented at the Design, Development \& Research, Cape Town.

Giardino, C., Bajwa, S. S., Wang, X., \& Abrahamsson, P. (2015). Key Challenges in Early-Stage Software Startups. Paper presented at the 16th International Conference on Agile Software Deelopment, Helsinki, Finland.

Glaubert, D., Nyffeler, N., \& Bergeron, L. (2018). Le design management dans les PME: une cartographie pour diagnistiquer les pratiques. Sciences de Design, 1(7).

Gorb, P. (1990). Design Management. New York: Van Nostrand Reinhold.

Hacklin, F., \& Wallin, M. W. (2013). Convergence and interdisciplinarity in innovation management: a review, critique and future directions. The Service Industries Journal, 33(7-8), 774-788. doi:10.1080/02642069.2013.740471

Ho, C.-H. (2001). Some phenomena of problem decompositionstrategy for design thinking: differences between novices and experts. Design Studies, 22, 27-45.

IDEO.org. (2015). The Field Guide to Human-Centered Design.

Knapp, J., \& Zeratsky, J. (2016). Sprint: How to Solve Big Problems and Test New Ideas in Just Five Days. New York, USA: Simon \& Schuster.

Kolko, J. (2007). The tenuous relationship between design and innovation. Artifact, 1(3), 198-203.

Leonard-Barton, D. (1995). Wellsprings of knowledge: building and sustaining sources of innovation. Boston: Harvard Business School Press.

Liedtka, J. (2014). Innovative ways companies are using design thinking. Strategy and Leadership, 42(2), 40-45.

Liedtka, J. (2018). Why Design Thinking Works. Harvard Business Review(September-October), 72-79.

Lockwood, T. (2007). Design Value: A Framework for Measurement. Design Management Review(Fall), 90-97.

Malins, J. P. (2011). Innovation by Design: Using Design Thinking to Support SME's. Paper presented at the The Endless End: The 9th International European Academy of Design Conference, Port, Portugal. http://openair.rgu.ac.uk

Mitchell, P. H. (2005). What's in a Name? Multidisciplinary, Interdisciplinary, and Transdisciplinary. Journal of Professional Nursing, 21(6), 332-334.

Monori, I., Arruda, A., \& Araujo, K. (2015, 26-30 July 2015). The design and technolgical innovation: how to understand the growth of startups companies in competitive business environment. Paper presented at the 6th International Conference on Applied Human Factors and Ergonomics (AHFE), Las Vegas, Nevada.

Na, H. J., Evans, M., Zitkus, E., Whicher, A., \& Walters, A. (2018). Design in Action: Understanding the Drivers and Barriers to Strategic Use of Design for Innovation. Paper presented at the 21st DMI Academic Design Management Conference, London.

Nguyen, Marianna (2016). 'Design Thinking in Startups', University of Oslo, Oslo.

Osterwalder, A., \& Pigneur, Y. (2014). Value Proposition Design: How to Create Products Hoboken, New Jersey, USA: John Wiley \& Sons Inc.

Owen, C. L. (2006). Design Thinking: Driving Innovation(Innovation). Retrieved from www.BPMInstitute.org 
Pisano, G. P. (2019). The hard truth about innovative cultures. Harvard Business Review, January-February 2019, 63-72.

Radovic-Markovic, M., \& Salamzadeh, A. (2012). The Nature of Entrepreneurship: Entrepreneurs and Entrepreneurial Activities. Saarbrcken, Germany: Lap Lambert Academic Publishing.

Ries, E. (2011). The Lean Startup: How Today's Entrepreneurs use Continuous Innovation to Create Radically Successful Businesses. USA: Crown Business.

Rosenfield, P. L. (1992). The Potential of Transdisciplinary Research for Sustaining and Extending Linkages between the Health and Social Sciences. Social Science and Medicine, 35, 1343-1357.

Rossanese, L., Zilse, R., Arantes, E., \& Tobias, R. (2017). Validate and Measure KPI Effectiveness in Design Thinking for Startups. e-Revista LOGO, 6(3), 17. doi:10.26771

Roy, R. (1994). Can the Benefits of Good Design be Quantified? Design Management Journal, 5(2), 9-17.

Sanders, E., \& Stappers, P. J. (2008). Co-creation and the new landscape of design. CoDesign, 4(1), 5-18.

Sanders, E., \& Stappers, P. J. (2013). Convivial Toolbox: Generative Research for the Front End of Design. Netherlands: Bis Publishers.

Schwartz, D. L., Bransford, J. D., \& Sears, D. (2005). Efficiency and innovation in transfer. In J. P. Mestre (Ed.), Transfer of Learning from a Modern Multidisciplinary Perspective (pp. 1-51). Greenwich, Conneticut: Information Age Publishing.

Seidel, V. P., \& Fixson, S. K. (2013). Adopting "Design Thinking in Novice Multidisciplinary Teams:The Application and Limits of Design Methods and Reflexive Practices. The Journal of Product Innovation Management, 30(S1), 19-33. doi:10.1111/jpim.12061

Sheppard, B., Kouyoumjian, G., Sarrazin, H., \& Dore, F. (2018). The Business Value of Design. The McKinsey Quarterly.

Stickdorn, M., \& Schneider, J. (2011). This is Service Design Thinking. Amsterdam: BIS Publishers.

Tschimmel, K. (2012). Design Thinking as an effective Toolkit for Innovation. Paper presented at the XXII3 ISPM Conference: Action for Innovation: Innovating from experience.

Ward, A., Runcie, E., \& Morris, L. (2009). Embedding innovation: design thinking for small enterprises. Journal of Business Strategy, 30(2/3), 78-84. doi:10.1108/02756660910942490 